\title{
A synoptic sampling method applied to Calanus finmarchicus population on the Norwegian mid-shelf in 1997
}

\author{
Ole-Petter Pedersen ${ }^{1, *}$, Kurt S. Tande ${ }^{1}$, Dag Slagstad ${ }^{2}$ \\ ${ }^{1}$ Norwegian College of Fishery Science, University of Tromsø, 9037 Tromsø, Norway \\ ${ }^{2}$ Sintef Automatic, 7034 Trondheim, Norway
}

\begin{abstract}
The majority of studies of marine processes are based on data from significant field efforts. This was also the case for the Trans-Atlantic Study of Calanus finmarchicus (TASC). Three cruises were conducted in 1997 as part of a field programme, covering the most important reproductive period of $C$. finmarchicus at the latitude of the Norwegian shelf. Conventional sampling provides distribution maps for selected life stages and species without taking into consideration errors introduced by internal rates of the biological components, behavior and advection. An understanding of physical-biological processes studied is best acquired by reconstructing a synoptic spatial distribution of plankton from samples including advective effects. We have developed a method for transforming conventionally sampled data into synoptic distributions (Synoptic Sampling Scheme, SSS transform) by removing the advective component. This is achieved by forward and backward Lagrangian particle tracking, both in physical xyz space and stage space. The method includes the application of hydrodynamical flowfields and physiological models featuring the population dynamics of $C$. finmarchicus. We have assessed the method by comparing and contrasting distribution maps based on untreated and normalised synoptic data on the demography of $C$. finmarchicus. The data were taken from 2 of the cruises conducted during the spring and summer of 1997 on the Norwegian mid-shelf sector. The results show that the lowest stages are more affected by the SSS transform than the older stages, due to shorter turnover time. Samples taken in regions with high current magnitudes contribute most to the reconfiguration of the cruise polygon. It is also shown that the SSS transform appears to have greater effects on small concentrations. The controlling factor is probably the fluxes amongst the stages. An effect indicated by the scheme is that the end regions will be most affected by the SSS, while the general ecological interpretations are not dramatically changed. Due to the effect advection and stage dynamics will have during the time of the cruise, the study recommends the use of new semi-synoptic sampling technology. This could eliminate the use of the SSS transform. To a certain extent the optical plankton counter (OPC) and acoustic Doppler current profiler (ADCP) could prove efficient in that context. Generally, interpretations based on uncorrected data should be made with extreme care.
\end{abstract}

KEY WORDS: Synoptic sampling • Calanus finmarchicus · Advection

\section{INTRODUCTION}

Historically, collecting field samples from one particular site over time has been the most frequently applied method to assess the demographic structures

*E-mail: olepp@nfh.uit.no in copepods (e.g. Mauchline 1998). Numerous studies based on time-series have established links between abundance, distribution and environmental factors (Barber \& Chavez 1983, Dickson et al. 1988, Taylor et al. 1992, Roemmich \& McGowan 1995), and these studies have provided a substantial amount of basic ecological knowledge. For areas dominated by advec- 
tion, the effect of environmental conditions on the population dynamics of copepods are integrated over time and mostly settled outside the particular sampling site. The identification of causal relations between environmental factors such as temperature and food and the resultant growth and generation patterns has consequently been a serious problem in plankton ecology (Mullins \& Brooks 1976, Paffenhöfer \& Harris 1976, McLaren 1978, Condrey 1982, Huntley \& Boyd 1984). For demographic studies of copepods under natural environmental conditions, it is therefore essential to design and conduct a 3D sampling programme which covers the temporal and spatial domains relevant to resolving generation patterns on more objective and solid grounds.

The patchy and temporal distribution of plankton in the ocean requires that the sampling is designed to meet the questions addressed. In a recent study off the Californian coast, the plankton distribution was timedependent, especially in regions where there were strong currents (Huntley at al. 1995). The time scales of the maximum and minimum values were considered to typically be in the range of 10 to $50 \mathrm{~d}$, but they were not necessarily longer than or similar to the time scales of physical processes (Zhou 1998). The relevant time scale in our study is approximately 4 mo and is determined by the generation time of Calanus finmarchicus, which is about $60 \mathrm{~d}$. In a model study of this species, Miller \& Tande (1993) estimated the minimum sampling time to be $1 \mathrm{wk}$, if one is to be able to track the moulting schedules for individual stages. This sampling frequency is unobtainable in a field study where the population may produce 2 generations over the productive period of $6 \mathrm{mo}$. As a compromise, therefore, we chose in this study a sampling scheme that aims at selecting those periods in which the species is considered to demonstrate strong cohorts of recruits. In order to determine how and when multiple generations are formed in C. finmarchicus, we conducted 3 separate cruises on the Norwegian mid-shelf during the spring, early summer and mid-summer of 1997, within the framework of the Trans-Atlantic Study of C. finmarchicus (TASC) (Pedersen et al. in press).

By estimating the spatial distribution of plankton at a given time, we may acquire a good understanding of planktonic processes. Observations show that plankton distribution is closely related to physical features such as circulation, eddies and upwelling areas (Huntley et al. 1995). This is of particular relevance to the present study, since our target area includes both on- and off-shelf waters from Møre in the south to Lofoten in the north, in the Norwegian mid-shelf sector. The bottom topography on the shelf varies extensively, with several prominent banks (i.e. Haltenbanken and Sklinnabanken), but the major part of the shelf has a bottom depth around 200 to $300 \mathrm{~m}$. At the shelf break there is a prominent topographical steering of the water currents, and sub-sea canyons operate as entry and drainage sites for the currents in the study area (see Pedersen et al. in press). The Norwegian mid-shelf region definitely has a complicated hydrography and current system, which is determined by the seasonal climatic conditions and variable bottom topography (Johannessen 1986, Poulain et al. 1996).

How do we correctly interpret the biological and physical data that have been obtained over cruise periods of several weeks, covering an area of several hundred $\mathrm{km}^{2}$ ? Conventional approaches provide distribution maps for selected life stages and species without taking into considerations errors introduced by the internal rates of the biological components, behavior and advection (e.g. Zhou 1998).

Very few studies, however, have addressed to what extent these 2D patterns objectively reflect the phenomena in question. The first step towards understanding the physical-biological processes is best accomplished by reconstructing a synoptic spatial distribution of plankton from samples including advective effects. This is the main objective of the present paper. We have developed a method for transforming conventionally sampled data into synoptic distributions, by removing the advective component. This is achieved by forward and backward Lagrangian particle tracking (Pedersen et al. in press), both in physical xyz space and stage space. The method includes the application of hydrodynamical flowfields and physiological models, featuring the population dynamics of Calanus finmarchicus. We have further assessed the method by comparing and contrasting the distribution maps from untreated and normalised synoptic data on the demography of $C$. finmarchicus for 2 of the cruises from spring and summer 1997 on the Norwegian mid-shelf sector. The paper evaluates the 2 approaches on the basis of various criteria, and recommends a methodology and a sampling design for future in situ population rate studies of zooplankton ecology.

\section{MATERIALS AND METHODS}

Three cruises, the first two with RV 'Jan Mayen' and the third with RV 'Johan Ruud'; were conducted in 1997 as a part of a field programme within the frame of TASC. The 3 cruises were timed to cover the most important productive period of $C$. finmarchicus. Consequently, Cruise 1 covered the spring spawning period (i.e. from April 7 to 19), Cruise 2 was estimated to cover the end of the $G_{1}$ generation (i.e. from May 28 to June 9), and Cruise 3 was expected to cover the realization of a potential $G_{2}$ (i.e. July 10 to 19 ). In this 
paper we shall only discuss the data from the first 2 cruises.

The study area covered the Norwegian mid-shelf sector from the Lofoten peninsula in the north $\left(\sim 68^{\circ} 30^{\prime} \mathrm{N}\right)$ to the shelf off Møre in the south $\left(\sim 63^{\circ} 30^{\prime} N\right)$. Since the cruises were planned to cover the shelf, the shelf break and the adjacent oceanic area (Fig. 1), the tracks were basically designed as transects crossing the shelf in the northern, mid- and southern region of the study area. The cruise tracks run upstream from north to south, crossing from west to east and back again (Fig. 1). The sampling programme was designed in order to obtain a minimum of 4 samples from the Atlantic Current (oceanic water), Norwegian Atlantic Current (shelf break), and Norwegian Coastal Current (NCC) (on-shelf water) (see Poulain et al. 1996, Pedersen et al. in press).

Zooplankton sampling. Zooplankton samples were obtained from 5 to 7 depth strata at selected stations (see Table 1) by a $1 \mathrm{~m}^{2}$ MOCNESS with a $180 \mu \mathrm{m}$ mesh size net towed at 1.5 knots. The zooplankton sampling was conducted upon arrival at the stations along the

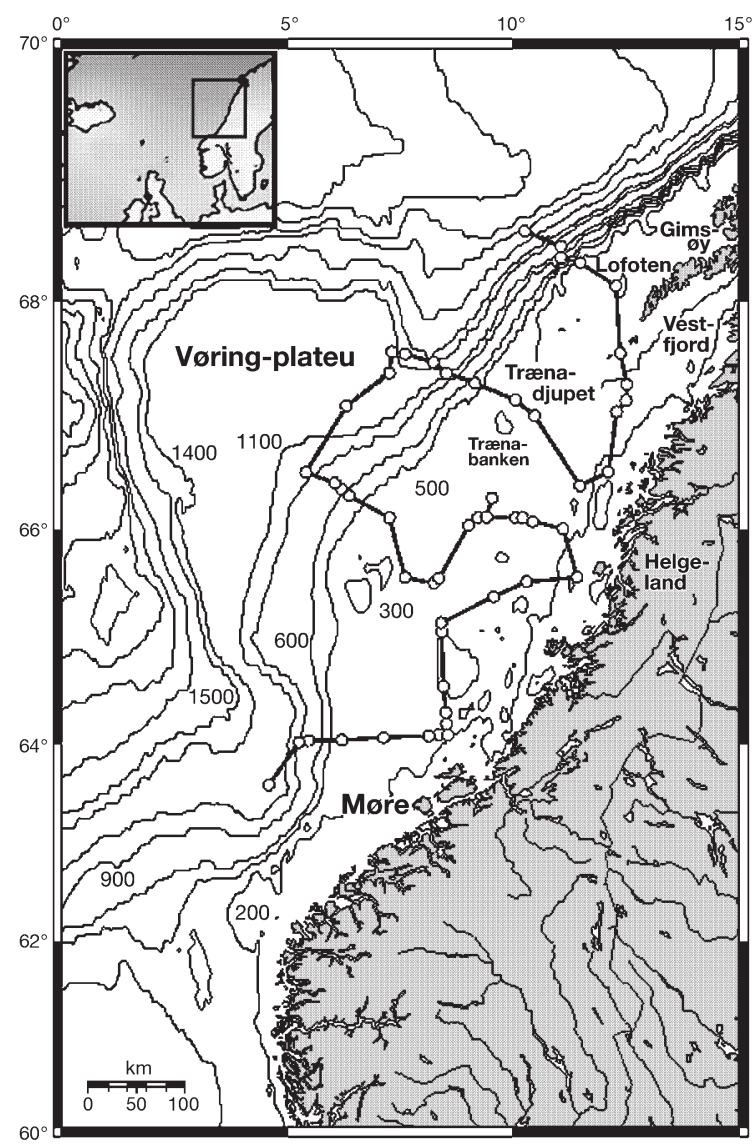

Fig. 1. The TASC study area on the Norwegian mid-shelf during 1997, with the principal cruise track (line) and sampling stations (o) indicated. ETOPO5 database used for contours cruise track, so vertical stratified samples were obtained from several time periods of the day. Nauplii were also quantitatively sampled by vertical hauls over the uppermost $100 \mathrm{~m}$ of the water column, by using a WP2 (90 $\mu \mathrm{m}$ mesh size) at selected stations. Each MOCNESS sample was split with a Motoda splitter device (Motoda 1959), and 1 portion was preserved in $4 \%$ formaldehyde in seawater buffered with hexamine. A bactericide, 1,5-propane-diol (5\% by volume), was added to the preservative. The other portion was then further divided; one part of it was stored in $>90 \%$ ethanol for molecular analysis, the other frozen in liquid nitrogen for later biomass analysis.

Copepod identification. The zooplankton preserved in formaldehyde was analyzed according to a protocol designed for this study. Initially gelatinous zooplankton was removed from the samples and their displacement volume measured. The larger animals (euphausiids, amphipods, caridea and fish larvae) were then removed and counted from whole samples. Calanus finmarchicus was the target species of the analysis. However, in certain areas there was a mixture of Calanus species that were difficult to identify to species levels (C. finmarchicus/C. helgolandicus or C. finmarchicus/C. glacialis). Before we started with the staging, the following test was carried out:

Before starting the sub-sampling and staging, at least 20 copepodite stage $C V, 20$ adult female and 20 adult male Calanus were identified to species level, or all of either stage present in the sample if $<20$ were available. If the 60 specimens were either all $C$. finmarchicus or all C. helgolandicus, the specimens were then replaced in the sample before further sub-sampling. Then, counting and stage identification were carried out. If there were less than approx. 200 Calanus in a sample, then all specimens were examined. If there were more than approx. 200 Calanus, then a sub-sample containing at least 100 Calanus was examined.

Counts were made for adult females, adult males and copepodite stages $\mathrm{CI}$, CII, CIII, CIV and CV, giving $\mathrm{CI}$ to CIV the status of Calanus spp. If C. finmarchicus were found to co-occur with $C$. helgolandicus or $C$. glacialis in 1 depth strata at the station, we nominated CI to CIV as Calanus spp. in all samples from that station, even if only CV and adult C. finmarchicus were observed in other depth strata.

In areas where there was likely to be a mixture of Calanus finmarchicus, C. glacialis and/or C. hyperboreus, at least 100 individuals were identified to stage and measured for cephalothorax lengths in each subsample. Species identification was made according to length criteria (see Hirche et al. 1994, Unstad \& Tande 1991). The 100 specimens were replaced in the sample, and sub-sampling and counts were made as described above. If C. glacialis or C. hyperboreus were found 
Table 1. A summary of the biological sampling during the 3 TASC-cruises in 1997. Time columns: (d.mo.yr), (h, GMT). Position columns are provided as latitudes and longitudes, while strata indicate how many strata were sampled by MOCNESS at that station. The strata are divided as following: $0-20,20-50,50-100,100-200,200-300,300-500$ and $500-800 \mathrm{~m}$

\begin{tabular}{|c|c|c|c|c|c|c|c|c|c|}
\hline Stn & Time & $\begin{array}{l}\text { Cruise } 1 \\
\text { Position }\end{array}$ & Strata & Time & $\begin{array}{l}\text { Cruise } 2 \\
\text { Position }\end{array}$ & Strata & Time & $\begin{array}{l}\text { Cruise } 3 \\
\text { Position }\end{array}$ & Strata \\
\hline 1 & $\begin{array}{l}\text { 8.4.97 } \\
02: 19\end{array}$ & $\begin{array}{l}68.5656 \\
10.2304\end{array}$ & 8 & $\begin{array}{l}29.05 .97 \\
18: 50\end{array}$ & $\begin{array}{l}69.0216 \\
10.5901\end{array}$ & 8 & $\begin{array}{l}\text { 14.07.97 } \\
00: 20\end{array}$ & $\begin{array}{l}66.4100 \\
11.4500\end{array}$ & 6 \\
\hline 2 & $\begin{array}{l}\text { 8.4.97 } \\
10: 42\end{array}$ & $\begin{array}{l}68.3041 \\
11.4825\end{array}$ & 7 & $\begin{array}{l}\text { 30.05.97 } \\
04: 24\end{array}$ & $\begin{array}{l}69.2852 \\
11.5314\end{array}$ & 5 & $\begin{array}{l}\text { 14.07.97 } \\
05: 11\end{array}$ & $\begin{array}{l}67.0148 \\
10.4459\end{array}$ & 5 \\
\hline 3 & $\begin{array}{l}\text { 8.4.97 } \\
15: 45\end{array}$ & $\begin{array}{l}68.1152 \\
12.2636\end{array}$ & 5 & $\begin{array}{l}30.05 .97 \\
09: 30\end{array}$ & $\begin{array}{l}68.1025 \\
12.2548\end{array}$ & 5 & $\begin{array}{l}14.07 .97 \\
15: 42\end{array}$ & $\begin{array}{c}67.3006 \\
9.1429\end{array}$ & 8 \\
\hline 4 & $\begin{array}{l}8.4 .97 \\
23: 50\end{array}$ & $\begin{array}{l}67.1512 \\
12.4850\end{array}$ & 6 & $\begin{array}{l}31.05 .97 \\
09: 34\end{array}$ & $\begin{array}{l}67.1420 \\
12.2050\end{array}$ & 5 & $\begin{array}{l}14.07 .97 \\
23: 45\end{array}$ & $\begin{array}{l}67.5361 \\
07.5900\end{array}$ & 8 \\
\hline 5 & $\begin{array}{l}\text { 9.4.97 } \\
05: 47\end{array}$ & $\begin{array}{l}66.4007 \\
11.4656\end{array}$ & 6 & $\begin{array}{l}31.05 .97 \\
14: 08\end{array}$ & $\begin{array}{l}66.4017 \\
11.4736\end{array}$ & 5 & $\begin{array}{l}15.07 .97 \\
10: 50\end{array}$ & $\begin{array}{c}66.5116 \\
5.4017\end{array}$ & 8 \\
\hline 6 & $\begin{array}{l}\text { 9.4.97 } \\
09: 49\end{array}$ & $\begin{array}{l}67.0117 \\
10.4533\end{array}$ & 5 & $\begin{array}{l}31.05 .97 \\
17: 52\end{array}$ & $\begin{array}{l}67.0059 \\
10.4516\end{array}$ & 5 & $\begin{array}{l}\text { 15.07.97 } \\
19: 10\end{array}$ & $\begin{array}{c}66.2471 \\
6.5348\end{array}$ & 7 \\
\hline 7 & $\begin{array}{l}\text { 9.4.97 } \\
18: 05\end{array}$ & $\begin{array}{c}67.3097 \\
9.1410\end{array}$ & 8 & $\begin{array}{l}\text { 01.06.97 } \\
04: 11\end{array}$ & $\begin{array}{c}67.2943 \\
9.2106\end{array}$ & 7 & $\begin{array}{l}\text { 16.07.97 } \\
02: 08\end{array}$ & $\begin{array}{c}65.5293 \\
8.2383\end{array}$ & 7 \\
\hline 8 & $\begin{array}{l}\text { 10.4.97 } \\
01: 07\end{array}$ & $\begin{array}{c}67.5419 \\
7.5899\end{array}$ & 8 & $\begin{array}{l}01.06 .97 \\
14: 33\end{array}$ & $\begin{array}{c}67.4656 \\
7.5239\end{array}$ & 8 & $\begin{array}{l}\text { 16.07.97 } \\
07: 20\end{array}$ & $\begin{array}{c}66.1130 \\
9.2055\end{array}$ & 5 \\
\hline 9 & $\begin{array}{l}10.4 .97 \\
14: 33\end{array}$ & $\begin{array}{c}66.5150 \\
5.3921\end{array}$ & 8 & $\begin{array}{l}\text { 02.06.97 } \\
01: 54\end{array}$ & $\begin{array}{l}66.5127 \\
05.3854\end{array}$ & 8 & $\begin{array}{l}\text { 16.07.97 } \\
11: 05\end{array}$ & $\begin{array}{l}66.1191 \\
10.1795\end{array}$ & 6 \\
\hline 10 & $\begin{array}{l}\text { 10.4.97 } \\
23: 04\end{array}$ & $\begin{array}{c}66.3133 \\
6.3656\end{array}$ & 8 & $\begin{array}{l}02.06 .97 \\
11: 10\end{array}$ & $\begin{array}{c}66.2738 \\
6.4704\end{array}$ & 7 & $\begin{array}{l}\text { 16.07.97 } \\
15: 05\end{array}$ & $\begin{array}{l}66.0141 \\
11.0934\end{array}$ & 6 \\
\hline 11 & $\begin{array}{l}11.4 .97 \\
15: 22\end{array}$ & $\begin{array}{c}65.5200 \\
8.2400\end{array}$ & 7 & $\begin{array}{l}\text { 02.06.97 } \\
21: 37\end{array}$ & $\begin{array}{c}65.5312 \\
8.2353\end{array}$ & 7 & $\begin{array}{l}\text { 16.07.97 } \\
20: 25\end{array}$ & $\begin{array}{l}65.3383 \\
10.4673\end{array}$ & 7 \\
\hline 12 & $\begin{array}{l}\text { 11.4.97 } \\
21: 00\end{array}$ & $\begin{array}{c}66.1210 \\
9.2102\end{array}$ & 5 & $\begin{array}{l}\text { 03.06.97 } \\
03: 11\end{array}$ & $\begin{array}{c}66.1124 \\
9.1931\end{array}$ & 5 & $\begin{array}{l}17.07 .97 \\
02: 41\end{array}$ & $\begin{array}{l}64.5316 \\
10.0267\end{array}$ & 6 \\
\hline 13 & $\begin{array}{l}\text { 12.4.97 } \\
01: 07\end{array}$ & $\begin{array}{c}66.2952 \\
9.5118\end{array}$ & 6 & $\begin{array}{l}\text { 03.06.97 } \\
08: 30\end{array}$ & $\begin{array}{l}66.1201 \\
10.1730\end{array}$ & 6 & $\begin{array}{l}\text { 17.07.97 } \\
10: 15\end{array}$ & $\begin{array}{c}64.0941 \\
8.3398\end{array}$ & 7 \\
\hline 14 & $\begin{array}{l}12.4 .97 \\
06: 31\end{array}$ & $\begin{array}{l}66.1152 \\
10.1909\end{array}$ & 6 & $\begin{array}{l}03.06 .97 \\
13: 30\end{array}$ & $\begin{array}{l}66.0154 \\
11.0800\end{array}$ & 6 & $\begin{array}{l}17.07 .97 \\
13: 18\end{array}$ & $\begin{array}{c}64.0749 \\
8.1202\end{array}$ & 7 \\
\hline 15 & $\begin{array}{l}12.4 .97 \\
11: 10\end{array}$ & $\begin{array}{l}66.0136 \\
11.1014\end{array}$ & 6 & $\begin{array}{l}\text { 03.06.97 } \\
21: 35\end{array}$ & $\begin{array}{l}65.3530 \\
10.3752\end{array}$ & 6 & & & \\
\hline 16 & $\begin{array}{l}15.4 .97 \\
14: 08\end{array}$ & $\begin{array}{c}65.1454 \\
8.4009\end{array}$ & 6 & $\begin{array}{l}04.06 .97 \\
00: 55\end{array}$ & $\begin{array}{l}65.1347 \\
10.2157\end{array}$ & 5 & & & \\
\hline 17 & $\begin{array}{l}15.4 .97 \\
18: 52\end{array}$ & $\begin{array}{c}64.5455 \\
8.4431\end{array}$ & 5 & $\begin{array}{l}04.06 .97 \\
04: 16\end{array}$ & $\begin{array}{l}64.5320 \\
10.0229\end{array}$ & 5 & & & \\
\hline 18 & $\begin{array}{l}\text { 16.4.97 } \\
03: 43\end{array}$ & $\begin{array}{c}64.1922 \\
8.5130\end{array}$ & 7 & $\begin{array}{l}\text { 04.06.97, } \\
07: 07\end{array}$ & $\begin{array}{l}65.0344 \\
9.2619\end{array}$ & 6 & & & \\
\hline 19 & $\begin{array}{l}16.4 .97 \\
09: 45\end{array}$ & $\begin{array}{c}64.0925 \\
8.3538\end{array}$ & 6 & $\begin{array}{l}04.06 .97 \\
10: 43\end{array}$ & $\begin{array}{l}65.1428 \\
08.4047\end{array}$ & 6 & & & \\
\hline 20 & $\begin{array}{l}16.4 .97 \\
17: 33\end{array}$ & $\begin{array}{c}64.0549 \\
7.1135\end{array}$ & 6 & $\begin{array}{l}04.06 .97 \\
14: 44\end{array}$ & $\begin{array}{l}64.5448 \\
08.4355\end{array}$ & 5 & & & \\
\hline 21 & $\begin{array}{l}17.4 .97 \\
01: 08\end{array}$ & $\begin{array}{c}64.0343 \\
5.4549\end{array}$ & 7 & $\begin{array}{l}\text { 04.06.97 } \\
20: 44\end{array}$ & $\begin{array}{l}64.1914 \\
08.5230\end{array}$ & 6 & & & \\
\hline 22 & $\begin{array}{l}17.4 .97 \\
06: 34\end{array}$ & $\begin{array}{c}63.5947 \\
4.5728\end{array}$ & 8 & $\begin{array}{l}\text { 05.06.97, } \\
01: 11\end{array}$ & $\begin{array}{l}\text { 64.0900, } \\
8.3400\end{array}$ & 6 & & & \\
\hline 23 & $\begin{array}{l}18.4 .97 \\
07: 05\end{array}$ & $\begin{array}{l}67.1502 \\
12.4814\end{array}$ & 6 & $\begin{array}{l}05.06 .97 \\
03: 44\end{array}$ & $\begin{array}{l}64.0740 \\
8.1220\end{array}$ & 6 & & & \\
\hline 24 & & & & $\begin{array}{l}05.06 .97 \\
08: 45\end{array}$ & $\begin{array}{c}64.0553 \\
7.1145\end{array}$ & 6 & & & \\
\hline 25 & & & & $\begin{array}{l}05.06 .97 \\
19: 14\end{array}$ & $\begin{array}{c}64.0250 \\
5.5031\end{array}$ & 7 & & & \\
\hline 26 & & & & $\begin{array}{l}05.06 .97 \\
23: 38\end{array}$ & $\begin{array}{c}64.0005 \\
4.5911\end{array}$ & 8 & & & \\
\hline 27 & & & & $\begin{array}{l}\text { 07.06.97 } \\
03: 07\end{array}$ & $\begin{array}{c}66.2951 \\
9.5313\end{array}$ & 5 & & & \\
\hline 28 & & & & $\begin{array}{l}07.06 .97 \\
09: 23\end{array}$ & $\begin{array}{l}66.4754 \\
10.2015\end{array}$ & 7 & & & \\
\hline 29 & & & & $\begin{array}{l}07.06 .97 \\
10: 54\end{array}$ & $\begin{array}{l}66.4807 \\
10.2056\end{array}$ & 7 & & & \\
\hline 30 & & & & $\begin{array}{l}07.06 .97 \\
12: 36\end{array}$ & $\begin{array}{l}66.4804 \\
10.2135\end{array}$ & 7 & & & \\
\hline 31 & & & & $\begin{array}{l}07.06 .97 \\
13: 40\end{array}$ & $\begin{array}{l}66.4802 \\
10.2115\end{array}$ & 7 & & & \\
\hline 32 & & & & $\begin{array}{l}07.06 .97 \\
14: 45\end{array}$ & $\begin{array}{l}66.4758 \\
10.2054\end{array}$ & 7 & & & \\
\hline
\end{tabular}


in the samples, the first 3 stages were recorded as belonging to Calanus spp. (i.e. Calanus spp. CI, CII, CIII), while the remaining instars were assigned to species.

Interpolation. The copepod and nauplii data were converted to concentration (i.e. no. $\mathrm{m}^{-3}$ ), both for each depth interval sampled by MOCNESS and for the entire water column. The stations were non-uniformly distributed with respect to time and space; therefore, certain regions had more stations than other areas. This calls upon some sort of interpolation technique of spatial and temporal data, in order to reveal biological structures not apparent by a mere inspection of the sampled data. Initially, the geographical co-ordinates of the stations were converted to polar-stereographic grid-coordinates, and a spatial uniform grid covering the sampling region was defined (Ådlandsvik \& Eriksrød 1997). The method of interpolation applied was a cubic spline method (spline with degree not exceeding 3) using continuous first- and second-order derivatives (Kreyszig 1988). The number of interpolation techniques applicable for spatial analysis of sampled data is considerable, and each technique implies different advantages and constraints, e.g. triangulation, naturalneighbor, inverse distance, kriging, objective mapping, minimum curvature techniques with various options and parameters. No single method is well suited for all purposes and datasets (Davis 1981a,b, Marcotte 1991, Ripley 1991, Watson 1992). In order to evaluate the method applied in this paper, a different method, featuring a combination of spline and Laplacian interpolation (Iversen 1983), was applied to the same datasets. The discrepancies between the isoplots produced were negligible, although Iversen's (1983) method contains features not included in our method, e.g. extrapolation.

Normalization. Sampling in an advective environment along a cruise track adds a temporal dimension to the sampled data. This means that every sample has a unique 4D ID tag with a geographic location and a time stamp. The visualization of sampled data has to consider both of these factors. By piping the sampled data directly into an isoplot procedure, we only consider the spatial component of the data, and we could be led to believe that the output actually reflects a snapshot of the variable we sampled at a certain point in time, and that this snapshot is correct with respect to space. This is not the case. The major point to consider is that all stations are advected continuously. Consequently, the geographic locations, including strata, change continuously with time. We have therefore devised a scheme for eliminating the time component from the data, thus reducing the ID tag to a 3D variable. By doing this, we receive an output that is actually a true snapshot of the sampled variable, and the geographic locations are correct, i.e. a synoptic sampling scheme. Thus it will appear as if we had taken samples from all stations on the cruise at the same point in time (Fig. 2). As a result of advection, the term 'station', and consequently the water column, is no longer applicable, since the different strata exhibit different current patterns. In this context, 2D plots were applied in the visual analysis of the population structure.

Initially, we selected a temporal point of zero, to which the isoplots were referred. For the first cruise, this was set at 11 April 1997, 18:00 h GMT. This point in time was the approximate cruise mid-point with respect to the number of stations included in the cruise, and it separated the stations into 2 entities: the first 11 stations before and the last 11 after this point. The same division was made for the second cruise as well. The temporal zero was set at 3 June 1997, 12:00 h GMT, with 13 stations before this point and 13 after. The last cruise was considerably shorter than the first and second ones, so the normalization procedure was not carried out. The active sampling period was just $4 \mathrm{~d}$, so adjusting for advection will have only a minor effect, both with respect to stage development and position.

The abundance and stage data for all stations were then applied as initial settings for a particle-tracking model (Pedersen et al. in press). All stations were then tracked towards the temporal zero; thus stations before this point were tracked forward. The stations sampled after the temporal zero were consequently backtracked. The tracking (forward and backward) was also performed in the stage space of Calanus finmarchicus. The stage development function applied was the Belehrádek relationship. The particle-tracking

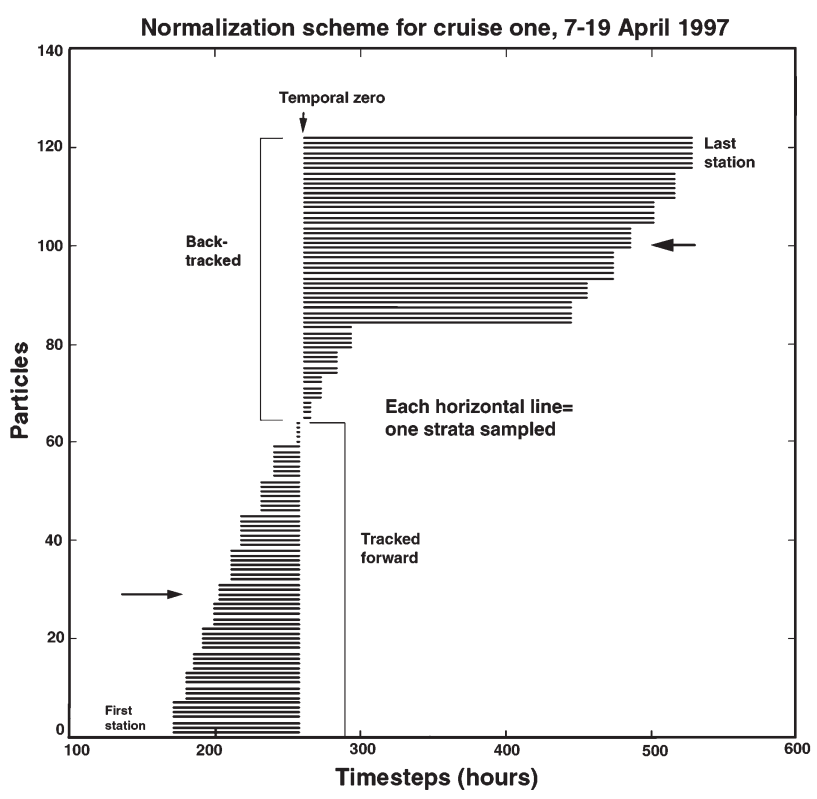

Fig. 2. Conceptual outline of the normalization approach, with indication of the temporal correction of the various stations sampled 
model incorporated 3 separate models: the SINMOD small-scale hydrodynamic model, the Princeton Ocean Model (POM) large-scale hydrodynamical model and a particle-tracking module using the Belehrádek function (Belehrádek 1935). SINMOD supplies the current fields applied, while the temperature fields applied are produced by the POM. All of these components are thoroughly described in Pedersen et al. (in press) and only a brief description is included here.

POM and SINMOD. POM was developed by Blumberg \& Mellor (1987) and modified by The Norwegian Meteorological Institute (DNMI) and the Institute of Marine Research (IMR), as documented in Ådlandsvik \& Eriksrød (1997). This large-scale hydrodynamical model is a 3D baroclinic ocean model with surface elevation, velocity, temperature and 2 variables for vertical mixing as model variables. In addition to the initial and boundary description of the model variables, the model forcing may include wind stress, air pressure, heat exchange with the atmosphere, tidal forcing and river run-off. The temporal resolution of the forcing is $6 \mathrm{~h}$, and the model domain has a horizontal resolution of $20 \mathrm{~km}$. The number of grid cells is $181 \times 120$.

The currents fields produced by SINMOD are used for the spatial advection. The horizontal grid point distance is $4 \mathrm{~km}$, while the flow fields are sampled every $2 \mathrm{~h}$. SINMOD as applied in the present study is comprehensively described in Slagstad (1987), Slagstad et al. (1989), Støle-Hansen \& Slagstad (1991), Slagstad \& Stokke (1994) and Slagstad \& Tande (1996). External forces driving SINMOD are density field, wind, air pressure and open boundary conditions (velocities and surface elevation) from a large-scale model. The environmental forcing is specific for 1997. Along the Norwegian coast there is substantial run-off from rivers, supplying fresh water into the shelf region. Through the VEINS project, POM has been evaluated by IMR for a section in the Barents Sea called the Bear IslandFugløya section $\left(70^{\circ} 30.00^{\prime} \mathrm{N}, 20^{\circ} 00.00^{\prime} \mathrm{E}\right.$ to $74^{\circ} 15.00^{\prime} \mathrm{N}$, $19^{\circ} 10.00^{\prime} \mathrm{E}, 20$ stations), for the time period 1996 to 1998. The numerical ocean model results are generally in agreement with observations made, and the simulated transports across this section are in accordance with previous knowledge (Asplin et al. 1998).

Biological model. The stage development model is built on a temperature function for stage duration $(d)$ derived from Corkett et al. (1986). The functional relationship is termed Belehrádek (Belehrádek 1935), and is given by:

$$
d=\alpha_{\mathrm{j}}(T+\xi)^{\gamma}
$$

The values for $\alpha_{j}$ are provided in Miller \& Tande (1993), and $T$ is the vertically and horizontally interpolated modelled temperature value. The parameters $\xi$ and $\gamma$ are fitted for a small set of rearing data, and the values 10.6 and -2.05 are used (Miller \& Tande 1993). Recently, laboratory results indicate that the above fitted values apply to Calanus finmarchicus grown under laboratory conditions (B. Campell pers. comm.). The Belehrádek function is found to agree with laboratory data, and tests carried out on real environments show that this function is realistic (McLaren 1978). Due to low diurnal migration amplitudes in high latitudes during the summer period (Falkenhaug et al. 1997), and the short simulation period in the set-ups (11 $\mathrm{d}$ for the spring and $10 \mathrm{~d}$ in early summer), the diurnal vertical migration (DVM) was neglected. In order to identify a possible DVM, we plotted the mean weighted depth (Falkenhaug et al. 1997) of each stage against the time of day for all stations for Cruises 1 and 2. There was no consistent pattern in the mean weighted depth for all copepodite stages and adults in the data, so we therefore ignored DVM in our tracking scheme. With respect to the quantity of copepods reaching adults, a preliminary analysis of $C$. finmarchicus from the study area (Arashkevich et al. unpubl.) shows that most of the CVs examined from Cruise 1 had fully developed gonads and gnathobases with apolysis in April, while in May/June, during Cruise 2, approx. $5 \%$ of the CVs were ready to moult. The normalization scheme was adjusted for each cruise so as to incorporate the moulting information presented above. This was technically done by allowing only a specified proportion (determined by the moulting fraction specified above) to proceed to adults. For example, in the second cruise, only $5 \%$ of the CVs were allowed to moult, and the rest were detained at copepodite stage $\mathrm{CV}$.

During the analysis of the biological data, we included, for practical reasons, copepodite stages CI to $\mathrm{CIV}$, although we were unable to identify them to a specific species level. This was done because the abundance of $\mathrm{CV}$ and adult Calanus glacialis and $C$. helgolandicus was very low on the Norwegian midshelf during the study period, with maximum numbers of C. glacialis in April and C. helgolandicus in July. At any time they were recorded to $<1 \%$ of $C$. finmarchicus (see Tande et al. unpubl.). Due to the short period simulated, we also assumed zero mortality. The sexratio was set to $50 \%$, indicating that moulting CVs split equally into male and females at this time of the year (Svensen \& Tande 1999).

\section{RESULTS}

\section{Synoptic sampling applied to Calanus finmarchicus: stage and spatial effects}

In order to study the effects of the synoptic sampling scheme (SSS), we have investigated the 2 cruises 
conducted in April and May/June 1997. Within each cruise, all stage distributions and the corresponding SSS distributions were plotted as pairs (Figs. 3 to 8). The 2D plots covered our study region. The cruise tracks were divided into 2 parts: one covering the forward region (FR) (red) and another covering the backward region (BR) (light blue). Since we sampled upstream in the study area, the northern region contains the forward part, the mid-region contains the temporal zero, while the southern region covers the backward part. In order to comprehend the SSS, it is of vital importance to realize the flow direction of organisms through stage space. Generally, in the backward part, a certain proportion within Stage $i$ will leave and enter Stage $i-1$, while a certain proportion will enter Stage $i$ from $i+1$. The reverse pattern will occur in the forward part.

\section{Cruise 1}

The distribution of Calanus finmarchicus during the first cruise in April 1997 demonstrates that plumes of CI to CII seem to prevail in areas close to Vestfjorden in the north-east, on the coast off Helgeland/Møre and in the shelf break region west of Møre (Fig. 3a,c). The corresponding SSS transform showed a reduced concentration of $\mathrm{CI}$ in the FR and in the BR, while the midregion (MR) was fairly unchanged (Fig. 3b). For the CII fraction, the changes were similar, showing a reduction in the BR, while there was an apparent increase in the FR (Fig. 3d). The largest concentration deviations were found on the northern and southern flanks of the study area. This was as expected, since we normalised approximately to the time midway through the cruise. The visual inspection showed that the shape of the cruise polygon had undergone minor changes. As expected, the advected datapoints followed the major current branches on the shelf and shelf edge, both forwards and backwards. The stretch was mainly in the north/south direction, since this is the major current direction in this region.

With respect to the CIII to CIV stages, the FR and BR were more affected by the SSS transform than was the MR. There was an increase in the concentration of CIIIs in the vicinity of the Lofoten region and south of Møre (Figs. 3a \& 4b). Initially CIVs were at a maximum at the shelf break (Fig. 4c). Under the SSS this maximum was strongly reduced, while the maximum southwest of Møre was virtually unaffected. With respect to distribution, the single dominant focus of the CIIIs was replaced by 3 separate foci, located in the FR, MR and $\mathrm{BR}$, while the CIV foci in the FR had vanished. The maximum abundance of the CIII to CIV fraction was fairly unchanged, while the geographic locations of the samples were more affected, with an appearance and disappearance of concentration foci mainly in the northern/southern part of the cruise polygon.

The non-transformed data of the CVs reveal a focus on the shelf break in the northern part of our study region, and a minor concentration in the southern region west of Møre (Fig. 5a), with a maximum of approximately 14 copepods $\mathrm{m}^{-3}$. The normalised data
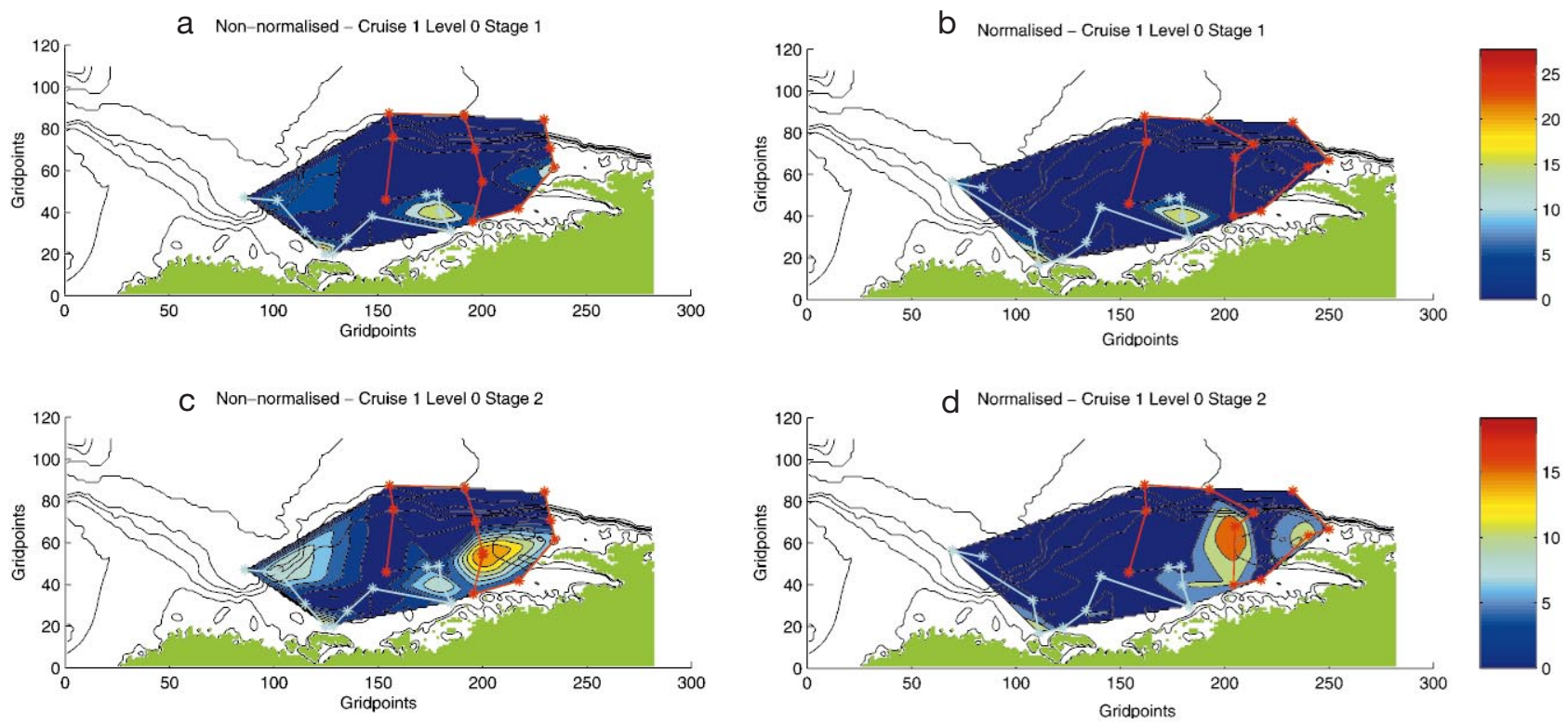

Fig. 3. Calanus finmarchicus. (a) Non-normalised horizontal distribution of $\mathrm{CI} \mathrm{m}^{-3}$ and (b) normalised distribution in the entire water column during Cruise 1, from 7 to 19 April 1997. (c) Non-normalised horizontal distribution of CII $\mathrm{m}^{-3}$ and (d) normalised distribution in the entire water column during Cruise 1, from 7 to 19 April 1997. Red track indicates forward region and light blue track indicates backward region 

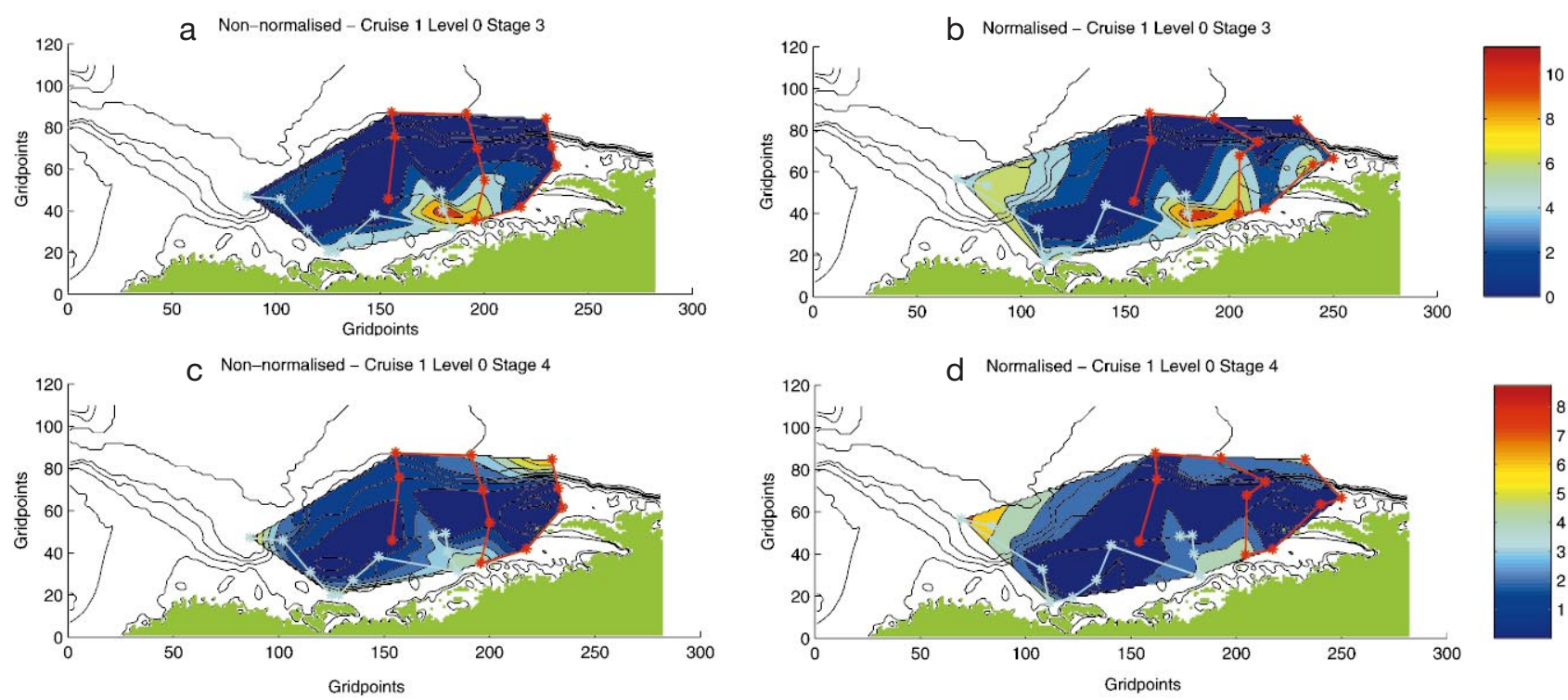

Fig. 4. Calanus finmarchicus. (a) Non-normalised horizontal distribution of CIII $\mathrm{m}^{-3}$ and (b) normalised distribution in the entire water column during Cruise 1, from 7 to 19 April 1997. (c) Non-normalised horizontal distribution of CIV $\mathrm{m}^{-3}$ and (d) normalised distribution in the entire water column during Cruise 1, from 7 to 19 April 1997. Red track indicates forward region and light blue track indicates backward region

show a major change of the original distribution (Fig. 5b), in which the southern focus is lost. This effect is caused by backtracking in stage space, indicating that a significant proportion of the CV has undergone a backwards stage progression and appears as CIV. The distribution of the adult females shows 1 dominant region in the south.

\section{Cruise 2}

During the second cruise in May/June, there were high numbers of recruiting $\mathrm{CI}$ to $\mathrm{CII}$ on the mid-shelf close to the coast of Helgeland (Fig. 6a,c). Compared to the first cruise, the maximum concentration had increased from 25 to 80 ind. $\mathrm{m}^{-3}$ for the CIs, and from
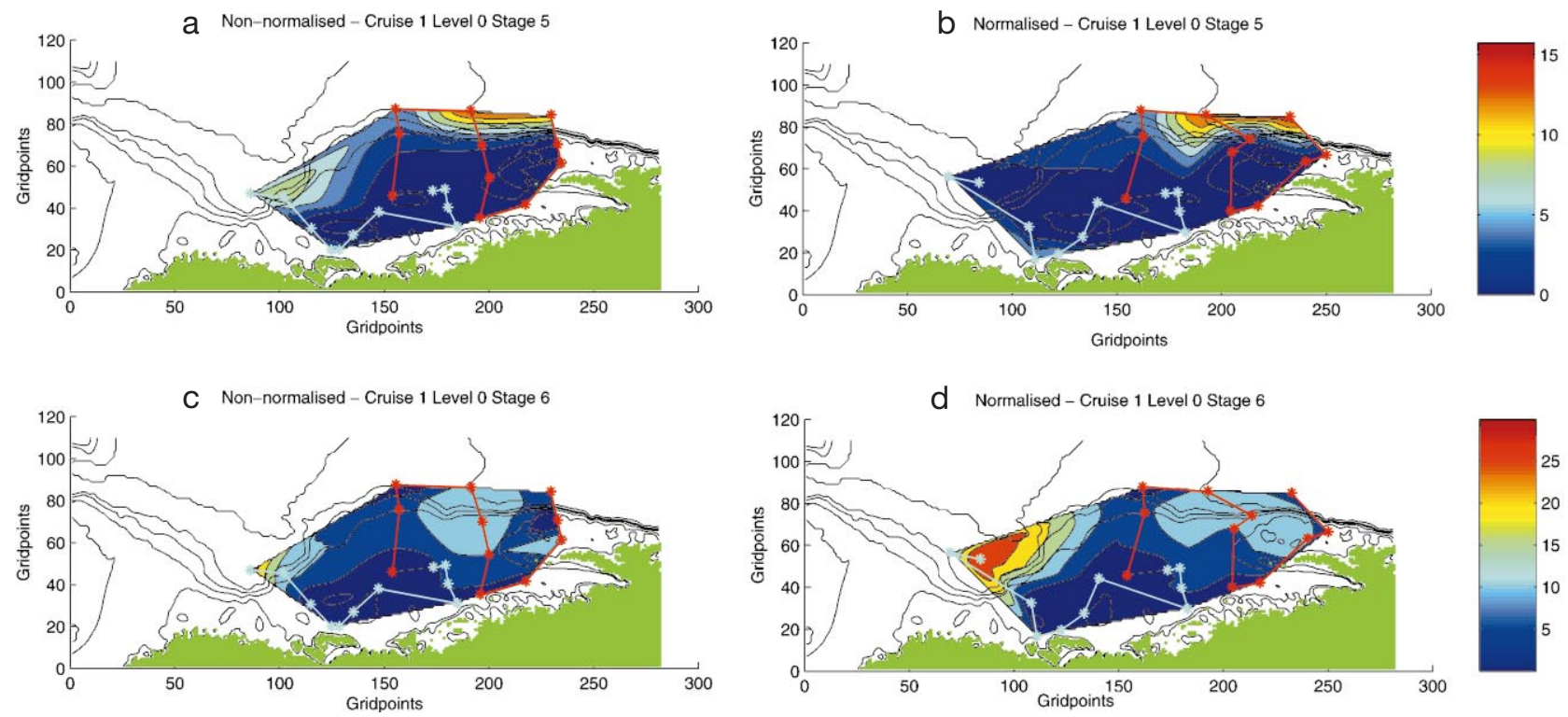

Fig. 5. Calanus finmarchicus. (a) Non-normalised horizontal distribution of $\mathrm{CV} \mathrm{m}^{-3}$ and (b) normalised distribution in the entire water column during Cruise 1, from 7 to 19 April 1997. (c) Non-normalised horizontal distribution of females $\mathrm{m}^{-3}$ and (d) normalised distribution in the entire water column during Cruise 1, from 7 to 19 April 1997. Red track indicates forward region and light blue track indicates backward region 
a Non-normalised-Cruise 2 Level 0 Stage 1

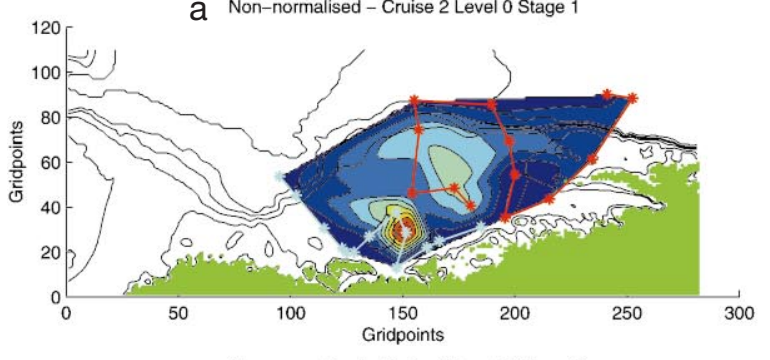

C Non-normalised-Cruise 2 Level 0 Stage 2

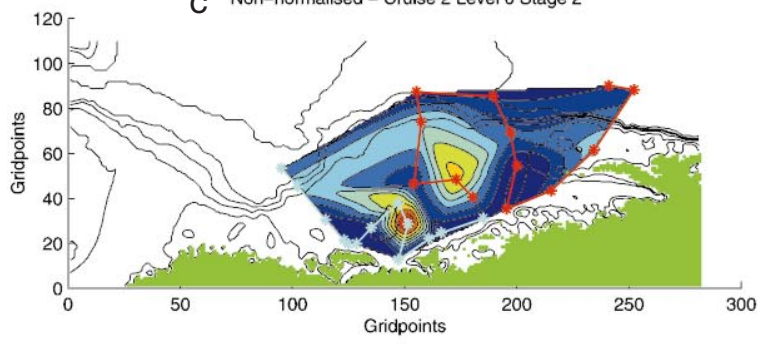

b Normalised - Cruise 2 Level 0 Stage 1

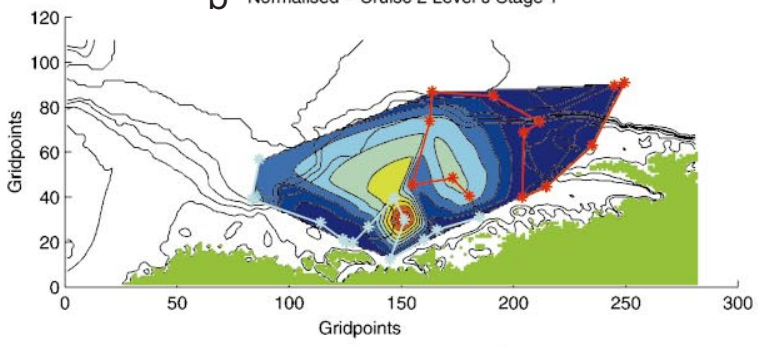

d Normalised - Cruise 2 Level 0 Stage 2

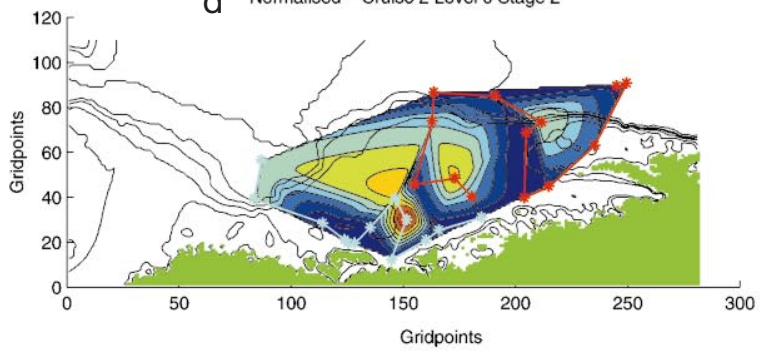

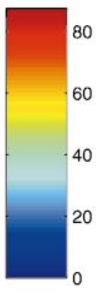

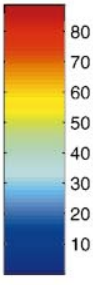

Fig. 6. Calanus finmarchicus. (a) Non-normalised horizontal distribution of $\mathrm{CI} \mathrm{m}^{-3}$ and (b) normalised distribution in the entire water column during Cruise 1, from 7 to 19 April 1997. (c) Non-normalised horizontal distribution of CII $\mathrm{m}^{-3}$ and (d) normalised distribution in the entire water column during Cruise 2, from 28 May to 9 June 1997. Red track indicates forward region and light blue track indicates backward region

15 to 80 ind $\mathrm{m}^{-3}$ for the CIIs. The untreated data show 2 concentration foci for the $\mathrm{CI}$ in the MR and BR (Fig. 6a), and this was conserved under the SSS. The major changes were found in the $\mathrm{BR}$, with a general increase in the concentration at the outer regions (Fig. 6b). This tendency was similar for the CIIs (Fig. 6c), with a general increase in the BR, though the effect was more pronounced. Additionally there were distributional changes in the FR, introducing a third isolated focus (Fig. 6d). As shown, there were obvious changes in the distribution, and as seen from Cruise 1, the cruise polygon had also changed. However, the effect of the advection of stations was also here minor compared to the observed dynamics in stage space.

The spatial distribution for the CIII component of the population showed 3 semi-separated foci with concentrations of copepods, located in the BR, MR and FR, with a high-concentration belt stretching along the shelf break (Fig. $7 \mathrm{a}$ ). This picture was drastically changed under the SSS transform. The high concentrations in the MR and FR remained approximately unchanged, while the concentration in the BR increased significantly (Fig. 7b). The original foci of the untreated data were not the dominant ones any more, although the abundance was approximately the same. The stability of the MR focus was expected, as this sample was located very close to the temporal zero, where the transformation effect is weak. The new dominant region of CIIIs was now the shelf break in the southern region. The non-transformed distribution of the CIVs indicated high concentrations along the shelf break in the south and north (Fig. 7c), while under the SSS, this pattern was transformed into 3 distinct peaks located in the $B R, M R$ and $F R$ (Fig. 7d).

The data from the second cruise showed that the highest numerical abundance was found in the CV age group (Fig. 8a), with major concentrations found at the shelfbreak in the BR stretching northwards and in the FR in the vicinity of Lofoten and Helgeland. The SSS showed an increased abundance in the northern FR and a reduction in the southern region (Fig. 8b). The adult females were mainly found in the NCC region along the coast, but the concentrations were low compared to the CVs (Fig. 8c). The SSS showed some insignificant changes (Fig. 8d).

Generally, the tendency with major changes in the BR/FR region was also found in Cruise 2. The results already identified in Cruise 1 with respect to the interplay between stage dynamics and advection, were also repeated in Cruise 2 . We should note that the systems investigated are initially highly heterogeneous with respect to the spatial distribution of the population, and that there is only weak spatial synchrony amongst the stages in both cruises. The comparison between Cruises 1 and 2 showed a spatial shift in the dominant region of females, together with an apparent reduction in concentration. The shift was shoreward, and the new peak concentrations were found in the coastal region in the $\mathrm{NCC}$ (Figs. 5c \& 8c). 

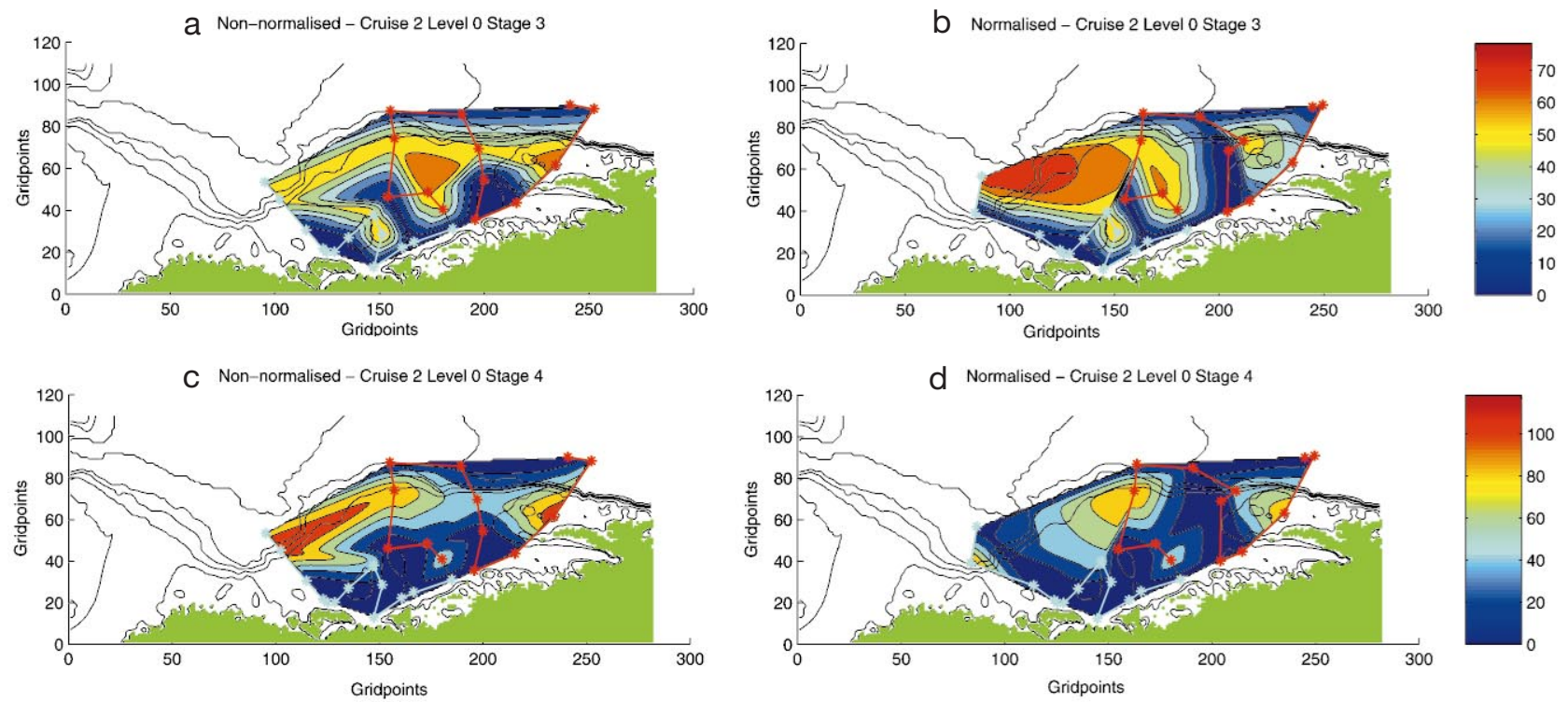

Fig. 7. Calanus finmarchicus. (a) Non-normalised horizontal distribution of CIII $\mathrm{m}^{-3}$ and (b) normalised distribution in the entire water column during Cruise 1 from 7 to 19 April 1997. (c) Non-normalised horizontal distribution of CIV $\mathrm{m}^{-3}$ and (d) normalised distribution in the entire water column during Cruise 2, from 28 May to 9 June 1997. Red track indicates forward region and light blue track indicates backward region

\section{DISCUSSION}

\section{Methodological considerations and constraints}

The original purpose of the cruises was to trace any consistent patterns in the horizontal distribution of the various life stages of Calanus finmarchicus at the Norwegian mid-shelf in 3 time windows during the productive season in 1997. Our sampling approach was based on conventional depth stratified net sampling with limited ship time and resources. The necessary compromises imposed obvious restrictions and pitfalls
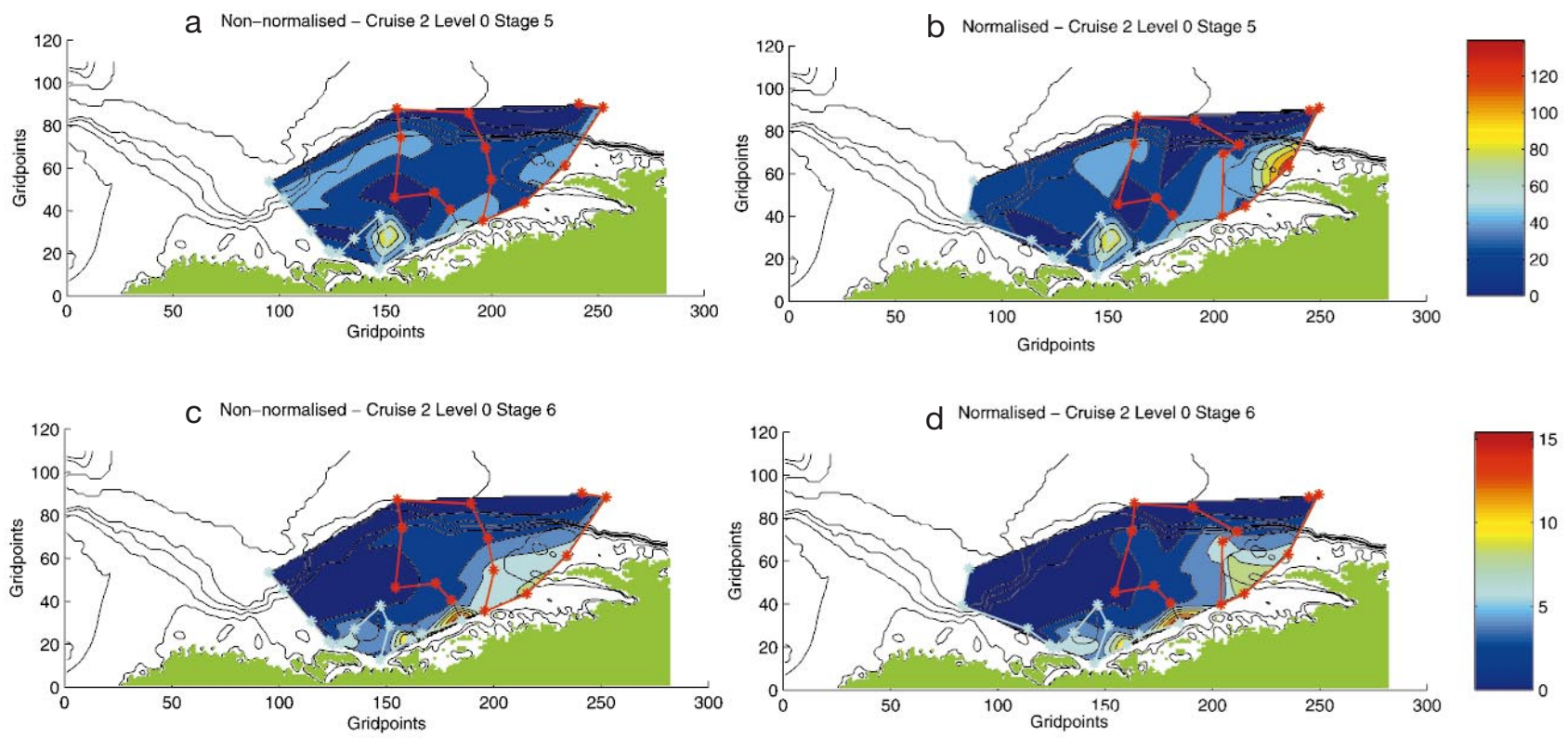

Fig. 8. Calanus finmarchicus. (a) Non-normalised horizontal distribution of $\mathrm{CV} \mathrm{m}^{-3}$ and (b) normalised distribution in the entire water column during Cruise 1, from 7 to 19 April 1997. (c) Non-normalised horizontal distribution of females $\mathrm{m}^{-3}$ and (d) normalised distribution in the entire water column during Cruise 2, from 28 May to 9 June 1997. Red track indicates forward region and light blue track indicates backward region 
with regard to our interpretations and abilities to draw solid conclusions with respect to the spatial distribution of the target species.

The sampling programme conducted enabled us to address physical-biological interactions on a mesoscale (between 1 and $1000 \mathrm{~km}$ in distance). Several studies have addressed the small-scale spatial distribution of plankton. These have demonstrated that the amplitude and frequency of the fluctuations in copepod densities can vary substantially over a distance of 30 to a few hundred meters (Smith et al. 1976). The average size of zooplankton heterogeneities on a meso-scale has been estimated to be close to 30-40 km in the Indian Ocean (Goldberg et al. 1997), where both advection and turbulent diffusion might facilitate an increase or a decrease in the size of these zooplankton patches. In our study area, one should bear in mind the combined role of advection and shelf topography in forming zooplankton patches of variable extension and duration. It is also important to be aware of the impact this will have on our ability to interpret the demography correctly.

A prerequisite for applying the method presented here is the availability of current fields covering the required time and space. The temporal resolution is a critical factor, as the time span of the entire simulation is relatively short (11 d at the most). In the SSS transform, we applied current fields produced by hydrodynamical models (SINMOD and POM) covering the time and space of the investigated region. The advection of objects was calculated by a particle-tracking algorithm used in previous studies (Pedersen et al. 1999 in press). The particle was defined so as to mirror the horizontal behavior of copepods. The generic forcing function for the Lagrangian particle-tracking algorithm was the current fields. Consequently, the reliability of the particle trajectories generated depended upon the ability of the hydrodynamical model to reproduce a realistic flow pattern in time and space. To validate a hydrodynamical model is a major task that is beyond the scope of this study, and there is no consistent set of rules applicable to such a goal (Asplin et al. 1998). The ideal verification procedure of such fields would be to make a comparison with current measurements covering the same space and time domain. Presently, this is not possible due to the immense efforts required for such a verification. However, the POM has been validated for the Fugløya section (at the entrance to the Barents Sea), providing current patterns in general accordance with stationary measurements. A similar quantitative approach has not been applied to the SINMOD, but to a certain extent, the qualitative assessment performed with respect to the current fields could compensate for this. The accumulated knowledge of the flow patterns on the Norwegian shelf and adjacent regions is in accordance with the simulated fields. The model also reproduces the amphidromic points observed at sea.

The other major component in the method developed is the biological model controlling the stage dynamics of Calanus finmarchicus. This model is based on the Belehrádek function (Eq. 1) and is controlled by temperature. Some uncertainties remain about the relative importance of temperature and food availability in determining the rates of growth and development in calanoid copepods (see Miller \& Tande 1993). Although food limitations can clearly occur in the field, at the moment we have only simulations of the temperature conditions. Sub-optimal food concentrations could potentially increase stage durations among copepods, but some of the studies dealing with this issue indicate that for marine copepods this factor has a greater effect on growth rate than on stage duration (see Vidal 1981). However, the growth function makes use of a set of parameters experimentally obtained, and it would be an extension of the results obtained to perform a sensitivity analysis in parameter space. In our model, we decided to ignore mortality. This is clearly a component that should be included in a future extension of the model, but our major argument against doing this is that we have no clear notion of the in situ mortality rate and how it varies among stages. Any number used would be a pure guess, and the topic would change into a sensitivity analysis of mortality rate in a synoptic sampling context.

\section{Ecological interpretations of non-transformed data}

In April, the distributions of life stages of Calanus finmarchicus in the study area showed a demography where CVs and adults from the over-wintering $\mathrm{G}_{0}$ were found along with $G_{1}$ nauplii (not shown in the figures) and CI to CIII recruits. In this area there were significant differences in abundance and age structure within the population. The distribution of CVs was similar to that for adult females, with the highest abundance found along the continental shelf, declining towards the mainland with a minimum in Vestfjorden $\left(68^{\circ} 00.00^{\prime} \mathrm{N}, 15^{\circ} 00.00^{\prime} \mathrm{E}\right)$. There was a low correlation in the abundance overlap of recruiting CI to CIII and adult females, although both groups matched strongly in the southwest. These differences in distribution may be generated if the 2 age groups are differently linked to the velocity fields via their preferred depth distributions. There was a pronounced earlier formation of the $\mathrm{G}_{1}$ generation in Vestfjorden and along the coastal regions compared to off Møre: high concentrations of CI to CIII in Vestfjorden and off Møre indicate a separation at the onset of spawning of about 2 to $3 \mathrm{wk}$. This 
may be indicative of an earlier start of the spring bloom in shallow waters in Vestfjorden and Helgeland compared to the other areas covered. It could also support the notion of a local stock diapausing in selected regions on the Norwegian shelf, giving rise to an early formation of the $\mathrm{G}_{1}$ generation along the coast.

During the second cruise in May/June, the population structure was characterized by a numerically important group of CI to CII located on the shelf proper, and a concentration of CIV to CV south of the Vøring Plateau and along the continental shelf. An obvious feature was the spatial synchrony obtained within the stages, for which the region with high concentrations of older stages was found along the shelf break. The younger copepodite stages were displaced in regions and above trenches that are known from hydrodynamical simulations to transport Atlantic water into the shelf. Comparing Figs. 5c \& 6c, which show similar patterns, reveals this feature. The consequence of this reasoning is that the stages have a common region of origin, but because of advection, the population is dispersed onto the shelf. These differences in distribution may be generated if the stages are differently linked to the velocity fields via their preferred depth distributions. A contradictory aspect is the lack of females along the shelf break, and the presence of females and CV in the inner coastal region. Skreslet \& Olsen (1998) suggest that the area outside Helgeland has an environmental setting that enables Calanus finmarchicus to spawn more or less continuously during the summer period. If this proves to be a consistent feature over years, then we may have locations on the shelf that generate pulses of recruits of variable intensity over the entire productive period. Local areas like this may therefore decrease the synchrony of the cohorts and thus modify the age structure within the population during the summer.

\section{Does normalization change our ecological interpretation?}

How relevant is our normalization technique for zooplankton communities, and does it provide new knowledge compared to a conventional presentation of abundance data biased by time and advection? Our main conclusion for the 2 cruises on the Norwegian mid-shelf in 1997 is as follows:

\section{Cruise 1}

The distributional heterogeneity seen during Cruise 1 for the younger copepodite stages was reduced under the SSS (Fig. 3a to c). The number of dominant regions for the CIs was reduced from 3 to 1 , while the CIIs experienced a reduction from 3 to 2 dominant foci. The spatial distribution showed that while untransformed data contained major abundances along the shelf break in the south, the transformed plots were dominated by the shelf abundances, i.e. the SSS produced a spatial shift with respect to the younger stages. Another effect observed was that the maximum amounts of copepods had not changed.

The opposite effect was seen for the CIIIs on this cruise (Fig. 4a,b). The initial focus on the shelf was extended to a multiple-focus scenario, with an additional major concentration in the south and a minor one in the north. For the CIVs, the situation was fairly unchanged, i.e. the spatial pattern and maximum abundance were invariant under the SSS transform. The reduction of foci was also seen in the distributions for the older stages (Fig. 5a,b). The CVs was mainly present in the northern and southern parts of the shelf break, while the SSS transform removed the southern focus. In this region, the CVs were probably backtracked to CIVs, without a sufficient replenishment from the adult group present in the same region (Fig. 5c). The analysis of adults could indicate an increase of abundance, but this apparent change is most likely an effect of interpolation. The maximum boundary point in the BR in Fig. 5c was advected into an interior point under the SSS. This shift in classification and position gives this maximum point more power in the interpolation, and consequently it appears as an increase of abundance. The increase of adults in the BR is theoretically impossible due to the lack of a stage above adults.

Generally, the advective part of the SSS transform reconfiguring the cruise track was negligible compared to the effect of the stage dynamics observed. However, certain regions, such as the shelf break, displayed currents with a higher magnitude compared to the adjacent region. Particle tracking simulations give reason to expect that samples taken in this region are prone to be advected long distances compared to samples taken in low-speed regions. Consequently, samples from high-speed regions will contribute most to the reconfiguration of the cruise-track and the modified layout of the cruise polygon (Figs. 3 to $8 \mathrm{a}-\mathrm{c}$ ). Nevertheless, the modification of the cruise track under the SSS had minor effects compared to stage dynamics.

With respect to spatial distribution, the most significant effects appeared in the stages CI to CIII (Fig. 4a to c). A possible explanation could be that the modeled stage duration time was shorter amongst the younger stages. According to the Belehrádek parameterization carried out in Miller \& Tande (1993), the CIVs and CVs have a rather long stage duration (about 7 and $14 \mathrm{~d}$ at 
$5^{\circ} \mathrm{C}$, respectively). This fact implies that in order to remove and replenish a major proportion within these stages, the simulation period must be increased. The total evaluation of the SSS transform for the first cruise indicated some changes with respect to spatial distribution. The major effect was the death and birth of new concentration foci, while the abundance was stable. However, the ecological interpretations based on untransformed data were generally the same.

\section{Cruise 2}

The changes seen for the CI to CII spatial distribution were minor (Fig. 6a to c). Compared to the first cruise, the effect of the SSS was apparently reduced. A possible explanation could be the increase in the numbers of all stages, which was observed on this cruise. Under such circumstances, small fluxes amongst the stages will have insignificant effects with respect to the plotting of spatial distribution. For the first cruise, the numbers were generally low, and small fluxes of copepods would have a relatively larger effect. The most profound effects on this cruise were found amongst the CIII to CIVs, where the southern region was supplied with a large proportion of CIIIs (Fig. $7 \mathrm{a}, \mathrm{b}$ ). This is explained by the fact that this region initially has a large component of CIVs, probably being backtracked into CIIIs. However, the CIV distribution was also sensitive to major changes by reducing the abundance at the southern focus and introducing a new one in the MR (Fig. 7c,d). The transformation introduced heterogeneity for this stage, which is contrary to what was seen for the CIs on Cruise 1. As observed from Cruise 1, the changes were minor amongst the older stages. This trend was also apparent for the CVs and adults during Cruise 2 (Fig. 8a to d). The CVs showed a net loss of copepods in the BR, caused by the lack of replenishment from the adults (Fig. 8c,d), while the adults were almost unaffected.

Splitting and stage dynamics under the SSS transform

From Fig. 2, we can see the splitting scheme for the transform applied to Cruise 1. Even though we divided the number of stations into 2 equal parts, it is apparent that the major portion of the time at sea was spent in the BR (south). Based on this observation, it is reasonable to expect a larger effect of the SSS transform in this region compared to the FR. The stage dynamics in the FR and BR under the SSS transform were influenced by the relationship between Stages $i-1, i$ and $i+1$. A major proportion of Stage $i$ appearing in the untreated visualization will most probably be partly present as Stage $i-1$ under the SSS in the BR, and opposite in the FR. An example of this feature is seen by comparing Fig. $7 \mathrm{C}$ and $7 \mathrm{~d}$, where a large proportion of CVs is backtracked to CIVs. However, the stage dynamics is causally controlled by temperature, which varies in time and space. The general pattern observed for all the investigated stages is the effect of the SSS in the regions encompassing the beginning and end of the cruises. This is seen by comparing, for example, Fig. 4a and b, where the FR and BR show changes under the SSS transform, while the MR is fairly unchanged.

To predict the outcome of the SSS transform when applied to an untreated data set is a rather difficult undertaking. There are numerous factors that separately influence the outcome. The major variables are the temporal and spatial length of the cruise and the current regime in the region, and how this regime reconfigures the cruise layout under the SSS transform. Other crucial factors are the stage distribution of the species under study, the abundance sampled and the temperature conditions in the study region. In general, the major effects of the SSS could be summarized as follows:

- The lowest stages were more affected by the transform compared to the older stages, due to shorter turnover time.

- Samples taken in regions with high current magnitudes contributed most to the reconfiguration of the cruise polygon.

- The SSS transform appears to have had larger effects on small concentrations. The controlling factor is probably the fluxes amongst the stages.

- The end regions were most affected by the SSS.

- The ecological interpretations were not dramatically changed.

- Stage dynamics were more important than advection.

\section{CONCLUSION}

This paper has addressed the effect of advection upon the traditional sampling and visualization of spatial distribution for the different stages of a population. We have proposed a scheme that has been termed the Synoptic Sampling Scheme (SSS). This scheme eliminates the timeline during a cruise. We have applied this transform to the distribution of Calanus finmarchicus on the Norwegian shelf in 1997. The SSS is based upon a particle tracking model and a biological model, which simulate the dispersion and stage development of a cohort of $C$. finmarchicus backwards and forwards along the timeline. The demographic data applied are derived from 2 cruises and the region covered is the Norwegian shelf and the adjacent oceanic area. 
A similar approach to the SSS transform has previously been applied to tidal correction sampling positions, covering patches of herring larvae (Heath et al. 1987). The method involved the application of current meter moorings. We have extended the scope of this approach by using biological and hydrodynamical models, which provide us with the ability to calculate the current at every point at the sampling grid. The technique applied in this study could prove to be better suited for cruises of longer duration, in areas with more pronounced advection along with stage progression. Interpretations based on uncorrected data should be made with extreme care. From the analysis performed, we have outlined several stages where the SSS introduces major changes in spatial distribution. However, it should also be kept in mind that the modelling tools used in the SSS transform are simplifications of the reality observed, and that they will inevitably introduce a bias, which is reflected in the visual presentations. In this context, the use of semi-synoptic sampling equipment such as OPC and ADCP is recommended, in order to reduce the effect of advection and eliminate the bias inherent in the modelling tools.

Acknowledgements. We thank the crew on board RV 'Jan Mayen' and RV 'Johan Ruud' for their help during the collection of the data and A. Edvardsen, J. T. Eilertsen, and E. Halvorsen for help at sea. This work is a contribution to the Trans-Atlantic Study of Calanus finmarchicus (TASC), which is supported by the European Commission contract no. MAS3-CT95-0039 and The Russian Fund for Fundamental Research, Project No. 99-05-65161.

\section{LITERATURE CITED}

Ådlandsvik B, Eriksrød G (1997) A hindcast simulation of currents in the Nordic Seas. Report, Institute Marine Research, Bergen

Asplin L, Ingvaldsen R, Loeng H, Ådlandsvik B (1998) Description and validation of a three-dimensional numerical model of the Nordic and Barents Seas. Fisken og havet 10:98

Barber RT, Chavez FP (1983) Biological consequences of the 1982-1983 El Ninõ. Science 222:1203-1210

Belehrádek J (1935) Temperature and living matter. Protoplasma Monogr 8:1-277

Blumberg AF, Mellor GL (1987) A description of a threedimensional coastal ocean circulation model. In: Heaps $\mathrm{N}$ (ed) Three-dimensional coastal ocean models. Coastal and Estuarine Sciences, Vol 4. American Geophysical Union, Washington, DC, p 1-16

Condrey RE (1982) Ingestion-limited growth of aquatic animals: the case for Blackman kinetics. Can J Fish Aquat Sci 39:1585-1595

Corkett CJ, McLaren IA, Sevigny JM (1986) The rearing of calanoid copepods Calanus finmarchicus (Gunnerus), C. glacialis Jaschnov and C. hyperboreus Kroyer with comments on the equiproportional rule. Nat Mus Can Syllogeus Ser 58:539-551
Davis JC (1981a) Statistical techniques in petroleum explorations. Communic Stat Theor Meth A10(15):1479-1503

Davis JC (1981b) Contour mapping SURFACE-II. Science 237:669-672

Dickson RR, Kelly PM, Colebrook JM, Wooster WS, Cushing DH (1988) North winds and production in the eastern North Atlantic. J Plankton Res 10:151-169

Falkenhaug T, Tande KS, Semenova T (1997) Diel, seasonal and ontogenetic variations in the vertical distribution of four marine copepods. Mar Ecol Prog Ser 149:105-115

Goldberg GA, Pointkovski SA, Williams R (1997) Zooplankton field heterogeneity formation on the mesoscale: elements of the theory and empirical characteristics. Ecol Model 96:41-49

Heath MR, MacLachlan PM, Martin JHA (1987) Inshore circulation and transport of herring larvae off the north coast of Scotland. Mar Ecol Prog Ser 40:11-23

Hirche HJ, Hagen W, Mumm N, Richter C (1994) The Northeast Water Polynia, Greenland Sea. III. Meso- and macrozooplankton distribution and production of dominant herbivorous copepods during summer. Polar Biol 14:491-503

Huntley ME, Boyd C (1984) Food-limited growth of marine zooplankton. Am Nat 124(4):455-478

Huntley ME, Zhou M, Nordhausen W (1995) Mesoscale distribution of zooplankton in the California Current in late spring, observed by Optical Plankton Counter. J Mar Res 53:647-674

Iversen T (1983) INTERPOL, an interactive program for interpolation, Report no. 83-2-K. SINTEF, Trondheim

Johannessen OM (1986) Brief overview of the physical oceanography. In: Hurdle BG (ed) The Nordic seas. SpringerVerlag, New York, p 103-127

Kreyszig E (1988) Advanced engineering mathematics. John Wiley and Sons, New York

Marcotte D (1991) Cokriging with MATLAB. Comp Geosci $17: 1265-1280$

Mauchline J (1998) The biology of calanoid copepods. In: Blaxter JHS, Southward AJ, Tyler PA (eds) Advances in marine biology, Vol 33. Academic Press, San Diego

McLaren IA (1978) Generation lengths of some temperate marine copepods: estimation, prediction and implications. J Fish Res Board Can 35:1330-1342

Miller CB, Tande KS (1993) Stage duration estimation for Calanus populations, a modelling study. Mar Ecol Prog Ser 102:15-34

Motoda S (1959) Devices of simple plankton apparatus. Mem Fac Fish Hokkaido Univ 7:73-94

Mullin MM, Brooks ER (1970) Growth and metabolism of two planktonic, marine copepods as influenced by temperature and type of food. In: Steele J (ed) Marine food chains. Oliver and Boyd Ltd, Edinburgh, p 74-95

Paffenhöfer GA, Harris RP (1976) Feeding, growth and reproduction of the marine planktonic copepod Pseudocalanus elongatus Boeck. J Mar Biol Assoc UK 56:327-344

Pedersen OP, Tande K, Slagstad D (in press) A model study of demography and spatial distribution of Calanus finmarchicus at the Norwegian coast. Deep-Sea Res

Poulain PM, Warn-Varnas A, Niiler PP (1996) Near surface circulation of the Nordic seas as measured by lagrangian drifters. J Geophys Res 101:18237-18258

Ripley B (1991) Spatial statistics. John Wiley \& Sons, Inc, New York

Roemmich D, McGowan J (1995) Climatic warming and the decline of zooplankton in the California Current. Science 267:1324-1326

Skreslet S, Olsen K (1998) The Norwegian Coastal Current frontal system, a spawning habitat of Calanus finmarchi- 
cus that forces yearclass formation in NE Arctic cod (Gadus morhua) by food-web telecommunication. ICES CM 1998/R:22

Slagstad D (1987) A 4-dimensional physical model of the Barents Sea. SINTEF Report STF48 F87013, Trondheim

Slagstad D, Stokke S (1994) Simulation of flow field, hydrography, ice cover and primary production in the northern Barents Sea. Fisken og havet 9:1-47 (in Norwegian)

Slagstad D, Tande KS (1996) The importance of seasonal vertical migration in the across shelf transport of Calanus finmarchicus. Ophelia 44:189-205

Slagstad D, Støle-Hansen K, Loeng H (1989) Density-driven currents in the Barents Sea calculated by a numerical model. Model Identif Control 11:181-190

Smith L, Miller CB, Holton RL (1976) Small-scale horizontal distribution of coastal copepods. J Exp Mar Biol Ecol 23: 241-253

Støle-Hansen K, Slagstad D (1991) Simulations of currents, ice melting and vertical mixing in the Barents Sea using a 3-D baroclinic model. Polar Res 10:33-44

Editorial responsibility: Thomas Kiørboe (Contributing Editor), Charlottenlund, Denmark
Svensen C, Tande K (1999) Sex change and female dimorphism in Calanus finmarchicus. Mar Ecol Prog Ser 176: 93-102

Taylor AH, Colebrook JM, Stephens JA, Baker NG (1992) Latitudinal displacements of the Gulf Stream and the abundance of plankton in the north-east Atlantic. J Mar Biol Assoc UK 72:919-921

Unstad K, Tande KS (1991) Depth distribution of Calanus finmarchicus and C. glacialis in relation to environmental conditions in the Barents Sea. Polar Res 10(2): 409-420

Vidal J (1981) Physioecology of zooplankton. I. Effects of phytoplankton concentration, temperature and body size on the growth rate of Calanus pacificus and Pseudocalanus sp. Mar Biol 56:111-134

Watson DF (1992) Contouring: a practical guide to analysis and display of spacial data. Pergamon Press, Oxford

Zhou M (1998) An objective interpolation method for spatiotemporal distribution of marine plankton. Mar Ecol Prog Ser 174:197-206

Submitted: March 16, 1999; Accepted: February 9, 2000 Proofs received from author(s): September 4, 2000 